\title{
Prospective evaluation of remifentanil-propofol mixture for total intravenous anesthesia: A randomized controlled study
}

\author{
MEFKUR BAKAN $^{1}$, TARIK UMUTOGLU ${ }^{2}$, UFUK TOPUZ ${ }^{1}$, \\ EMINE YILMAZ GULER ${ }^{3}$, HARUN UYSAL ${ }^{4}$ and ERDOGAN OZTURK ${ }^{5}$
}

\author{
${ }^{1}$ Department of Anesthesiology, Vocational School of Health Services, Istanbul Rumeli University, Silivri, \\ Istanbul 34570; ${ }^{2}$ Deparment of Anesthesiology, Istanbul Health and Technology University, Zeytinburnu, \\ Istanbul 34015; ${ }^{3}$ Department of Anesthesiology, Ministry of Health Haseki Training and Research Hospital, \\ Fatih, Istanbul 34130; ${ }^{4}$ Department of Anesthesiology, Bezmialem Vakif University, Fatih, Istanbul 34093; \\ ${ }^{5}$ Department of Anesthesiology, Türk Böbrek Vakfı Memorial Hizmet Hospital, Bahçelievler, Istanbul 34180, Turkey
}

Received April 1,2020; Accepted January 18, 2021

DOI: $10.3892 /$ etm.2021.10632

\begin{abstract}
Application of total intravenous anesthesia (TIVA) may be considered as unpractical when compared with inhalational anesthesia. Although it is mostly not recommended, mixing intravenous agents is popular in clinical practice. The aim of the present study was to investigate the suitability of using remifentanil-propofol mixture (MIXTIVA) for TIVA. Adult patients with an American Society of Anesthesiologists grade of I-II scheduled for elective thyroidectomy were randomly allocated to 3 groups ( $n=32$ for each) to receive TIVA with remifentanil and propofol infusions separately (control group, Group I) or with MIXTIVA infusion that contained remifentanil/propofol at a proportion of $2 / 1,000$ or 3/1,000 (remifentanil concentration, 20 or $30 \mu \mathrm{g} / \mathrm{ml}$ in $1 \%$ propofol in Group II or Group III, respectively). The extubation time (the primary outcome of the study), the orientation time and number of patients in whom intraoperative hypotension, hypertension or bradycardia episodes were encountered during anesthesia were comparable among the groups. The mean remifentanil infusion rate in Group III was significantly higher than that in the other groups. The mean propofol infusion rates and mean bispectral index (BIS) scores during anesthesia were comparable among groups. Hypotension accompanied with a high BIS was encountered in one patient in Group III. In conclusion, compared to the standard TIVA technique using separate drug infusions, MIXTIVA infusion used for thyroidectomies did not result in any statistically significant difference in recovery and clinical outcomes. This
\end{abstract}

Correspondence to: Dr Mefkur Bakan, Department of Anesthesiology, Vocational School of Health Services, Istanbul Rumeli University, Mehmet Silivrili Cad. 38, Silivri, Istanbul 34570, Turkey E-mail: mefkur@yahoo.com

Key words: total intravenous anesthesia, propofol, remifentanil, propofol-remifentanil mixture, intravenous admixture, bispectral index monitoring technique may be considered as a practical implementation for busy ambulatory centers performing general anesthesia. The present study was retrospectively registered at clinicaltrials. gov (trial registration no. NCT04394897).

\section{Introduction}

The advantages of total intravenous anesthesia (TIVA) over inhalational anesthesia are well recognized (1). However, the use of TIVA during daily clinical practice is limited in certain instances. The application of TIVA may be considered as unpractical when compared with inhalational anesthesia. Preparation of the drugs for infusion may be time-consuming and in addition, TIVA requires infusion pumps, infusion sets and connecting tubes that increase the cost. The management of infusion rates during anesthesia maintenance is not straightforward when converting ' $\mu \mathrm{g} / \mathrm{kg} / \mathrm{min}$ ' or ' $\mathrm{mg} / \mathrm{kg} / \mathrm{h}$ ' to ' $\mathrm{ml} / \mathrm{h}$ '.

Remifentanil and propofol are commonly used for TIVA due to their characteristics of ease of titration, as well as rapid onset and offset of action. It may be more appropriate to use remifentanil and propofol with target-controlled infusion (or 'smart') pumps and monitoring using processed electroencephalographic signals, but access to such devices is limited. In general practice, remifentanil and propofol infusions are usually adjusted according to clinical signs of depth of anesthesia with the guidance of manual infusion schemes that have been proposed to maintain a constant blood concentration during anesthesia, depending on the pharmacokinetics (2).

As a practical implementation for TIVA, using remifentanil and propofol as a mixture at proper concentrations allows managing one infusion instead of two and has been described in the literature (1,3-18) and certain textbooks (19-22) and has been suggested by various institutes (23-25). Studies on the stability and compatibility of drugs in the remifentanil-propofol mixture (MIXTIVA) are conflicting $(26,27)$. However, in clinical practice, there may be other possible drawbacks of this technique: When infusing drugs as a mixture, when it is intended to administer one drug at a certain infusion rate, 
the other drug may be overdosed or its blood concentration may not reach the therapeutic level. The aim of the present study was to investigate the applicability and possible disadvantages of MIXTIVA infusion for the maintenance of TIVA and the changes in clinical outcomes when compared with the standard technique using propofol and remifentanil infusions separately.

\section{Materials and methods}

Patients. The present prospective randomized controlled trial was performed at Bezmialem Vakıf University Medical Faculty (Istanbul, Turkey) between January 2013 and April 2014. After approval by the Bezmialem Vakif University Ethics Committee (reference no. 71306642/050-01-04), patients aged 18-65 years scheduled for elective thyroidectomy and with an American Society of Anesthesiologists (ASA) physical status of I or II were included in the present study. The exclusion criteria were as follows: ASA physical status of III or above; a body mass index $>35 \mathrm{~kg} / \mathrm{m}^{2}$; pregnant, breast-feeding or menstruating females; patients who were not euthyroid; uncontrolled hypertension; hepatic, renal or cardiac insufficiency; alcohol, opioid or drug abuse; allergy or contraindication to any of the study drugs. Investigators MB and UT recruited the patients and written informed consent was obtained from each patient prior to randomization.

Drug preparation. Remifentanil (Ultiva; GlaxoSmithKline) was diluted with sterile water and the concentration of the reconstituted solution was $1 \mathrm{mg} / \mathrm{ml}$. The remifentanil-propofol mixture MIXTIVA was prepared in a 50-ml bottle of propofol $1 \%$ (Fresenius Kabi) by adding either 1 or $1.5 \mathrm{mg}$ of remifentanil to achieve a remifentanil concentration of 20 or $30 \mu \mathrm{g} / \mathrm{ml}$ and a remifentanil/propofol proportion of $2 / 1,000$ or $3 / 1,000$, respectively. Mixtures were always prepared immediately prior to administration, checked for visual stability to verify that they exhibited no evidence of precipitation or separation and used within $2 \mathrm{~h}$ of preparation. All infusions were administered with an Alaris GW Volumetric Pump (Cardinal Health) using an Alaris infusion set.

Randomization and blinding. Patients were randomly allocated to 3 groups to either receive anesthesia maintenance with remifentanil and propofol infusions separately (control group, Group I) or with MIXTIVA infusion with a remifentanil/propofol proportion of $2 / 1,000$ or 3/1,000 (Group II or Group III, respectively). Simple randomization was performed using 96 opaque sealed envelopes, 32 for each group, indicating group assignments. Prior to anesthesia induction, an anesthesiologist (TU) opened the next envelope and prepared the study medications. This anesthesiologist was not involved in preoperative and postoperative data collection or anesthesia management of the patients. Resident anesthesiologists (EYG and HU) who were blinded to the study groups (Group II and III) performed all procedures.

Surgical preparation of patients. Patients received all of their regular medications on the morning of surgery. On arrival at the operating room, ECG, noninvasive blood pressure (at the ankle), pulse oximetry, temperature and bispectral index (BIS;
Aspect Medical Systems) monitoring were applied. After premedication with intravenous (i.v.) midazolam (0.03 mg/kg), baseline heart rate and mean arterial blood pressure (MAP) values, were determined as the average of three consecutive measurements. Noninvasive blood pressure (NIBP) was assessed with intervals at least 3 min during anesthesia and BIS scores at the time of NIBP measurements were automatically recorded. An intravenous crystalloid solution (Isolyte-S; Koçak Farma İlaç ve Kimya Sanayi A.Ş) was administered as a $5-\mathrm{ml} / \mathrm{kg}$ bolus prior to induction and infusion at $5 \mathrm{ml} / \mathrm{kg} / \mathrm{h}$ was started.

Anesthesia. Induction of anesthesia was as follows: In Group I, remifentanil $(30 \mu \mathrm{g} / \mathrm{ml})$ and propofol $1 \%$ were prepared for infusion separately and both started at $0.5 \mathrm{ml} / \mathrm{kg} / \mathrm{h}$. In Group II and III, MIXTIVA infusion at $0.5 \mathrm{ml} / \mathrm{kg} / \mathrm{h}$ was started. All patients received lidocaine $1 \mathrm{mg} / \mathrm{kg}$, propofol $1.5 \mathrm{mg} / \mathrm{kg}$ and vecuronium $0.1 \mathrm{mg} / \mathrm{kg}$. At the 4th min of infusions, intubation was performed.

For anesthesia maintenance, in Group I, remifentanil infusion was adjusted to maintain the MAP within $\pm 20 \%$ of the baseline value (preferably under the baseline value) and the propofol infusion rate was adjusted to maintain the BIS between 30 and 50 (target: 40). In Group II and III, the primary goal of anesthesia management was to maintain the MAP within $\pm 20 \%$ of the baseline value (preferably under the baseline value) by adjusting MIXTIVA infusion between $0.3-1.2 \mathrm{ml} / \mathrm{kg} / \mathrm{h}$ (dose chart for MIXTIVA infusion is provided in Table I). When the MAP was above the baseline value, MIXTIVA infusion was increased with a $0.5-1 \mathrm{ml}$ bolus administration. When the MAP was within $\pm 20 \%$ of the baseline value, the secondary goal was to maintain BIS values between 30 and 50 (target: 40). Intravenous crystalloid infusion was also adjusted to maintain the MAP within the desired levels.

In case of hypotension (defined as MAP $<60 \mathrm{mmHg}$ ), anesthesia infusions were decreased or stopped for 1-2 min, i.v. bolus crystalloid infusion $3-5 \mathrm{ml} / \mathrm{kg}$ was administered and if hypotension persisted in two consecutive measurements, norepinephrine 5-10 $\mu \mathrm{g}$ was administered. When hypotension was accompanied with BIS values $>60$, ketamine $20-30 \mathrm{mg}$ was administered. In case of hypertension (defined as systolic arterial pressure $\geq 150 \mathrm{mmHg}$ persisting in two consecutive measurements despite maximum infusion rates), a bolus dose of 0.1-0.2 mg nitroglycerine was administered i.v. Bradycardia (heart rate $<45 \mathrm{bpm}$ ) was treated with atropine $0.5-1 \mathrm{mg}$ i.v.

The lungs were mechanically ventilated with a mixture of oxygen and air (fraction of inspired $\mathrm{O}_{2}, 50 \%$; tidal volume, $6-8 \mathrm{ml} / \mathrm{kg}$; respiratory rate, $10-14 / \mathrm{min}$ ) to obtain an end-tidal $\mathrm{CO}_{2}$ value between 30 and $35 \mathrm{mmHg}$.

Other medications. All patients received intravenous dexamethasone $8 \mathrm{mg}$, metoclopramide $10 \mathrm{mg}$, ranitidine $50 \mathrm{mg}$ and dexketoprophen trometamol $50 \mathrm{mg}$ after anesthesia induction; tramadol $100 \mathrm{mg}$ and paracetamol $1 \mathrm{~g}, 15 \mathrm{~min}$ before the end of surgery. In addition, skin infiltration with lidocaine $2 \%$ was achieved prior to surgical incision. Additional vecuronium was preferably not used after the induction dose to retain the option of recurrent laryngeal nerve monitoring. All infusions were terminated during skin closure and residual neuromuscular 
Table I. Dose chart for remifentanil-propofol mixture (MIXTIVA).

\begin{tabular}{|c|c|c|c|c|}
\hline Infusion rate, $\mathrm{ml} / \mathrm{kg} / \mathrm{h}$ & $\begin{array}{l}\text { Infusion } \\
\text { rate }^{\mathrm{a}}, \mathrm{ml} / \mathrm{h}\end{array}$ & $\begin{array}{c}\text { Propofol }{ }^{\mathrm{b}} \text { dose } \\
\mu \mathrm{g} / \mathrm{kg} / \mathrm{min}(\mathrm{mg} / \mathrm{kg} / \mathrm{h})\end{array}$ & $\begin{array}{c}\text { Remifentanil }^{\mathrm{c}} \\
\text { dose, } \mu \mathrm{g} / \mathrm{kg} / \mathrm{min}\end{array}$ & $\begin{array}{c}\text { Remifentanil }^{\mathrm{d}} \\
\text { dose, } \mu \mathrm{g} / \mathrm{kg} / \mathrm{min}\end{array}$ \\
\hline 1.2 & 84 & $200(12)$ & 0.4 & 0.6 \\
\hline 1 & 70 & $166(10)$ & 0.33 & 0.5 \\
\hline 0.8 & 56 & $133 \quad(8)$ & 0.26 & 0.4 \\
\hline 0.6 & 42 & $100(6)$ & 0.2 & 0.3 \\
\hline 0.5 & 35 & $83 \quad(5)$ & 0.17 & 0.25 \\
\hline 0.4 & 28 & $66 \quad(4)$ & 0.13 & 0.2 \\
\hline 0.3 & 21 & $50 \quad(3)$ & 0.1 & 0.15 \\
\hline
\end{tabular}

${ }^{\mathrm{a}}$ Example calculated for a patient weighing $70 \mathrm{~kg}$. ${ }^{\mathrm{b}}$ Given as $1 \%$ solution. ${ }^{\mathrm{c}}$ Given as $20 \mu \mathrm{g} / \mathrm{ml}$ solution. ${ }^{\mathrm{d}}$ Given as $30 \mu \mathrm{g} / \mathrm{ml}$ solution.

Table II. Demographic characteristics of patients.

\begin{tabular}{|c|c|c|c|c|}
\hline Item & Group I $(\mathrm{n}=32)$ & Group II (n=32) & Group III $(\mathrm{n}=32)$ & P-value \\
\hline Sex (male/female) & $6 / 26$ & $7 / 25$ & $4 / 28$ & NS \\
\hline Age (years) & $44.6 \pm 11.4(40.5-48.7)$ & $46.1 \pm 10.8(42.2-50)$ & $42.4 \pm 11.6(38.3-46.6)$ & NS \\
\hline Body weight (kg) & $76.3 \pm 16(70.5-82.1)$ & $74.4 \pm 15.6(68.8-80.1)$ & $71.7 \pm 14(66.6-76.7)$ & NS \\
\hline Body height (m) & $1.65 \pm 0.09(1.62-1.68)$ & $1.65 \pm 0.08(1.62-1.68)$ & $1.65 \pm 0.07(1.63-1.68)$ & NS \\
\hline $\operatorname{BMI}\left(\mathrm{kg} / \mathrm{cm}^{2}\right)$ & $28 \pm 4.8(26.2-29.7)$ & $27.3 \pm 4.6(25.6-29)$ & $26.2 \pm 4.2(24.7-27.7)$ & NS \\
\hline ASA I/II & $25 / 7$ & $26 / 6$ & $29 / 3$ & NS \\
\hline
\end{tabular}

Values are expressed as the mean \pm standard deviation ( $95 \%$ confidence interval) or absolute number of patients. BMI, body mass index; ASA, American Society of Anesthesiologists; NS, not significant ( $\mathrm{P}>0.05)$.

blockade was antagonized with neostigmine $0.05 \mathrm{mg} / \mathrm{kg}$ and atropine $0.02 \mathrm{mg} / \mathrm{kg}$.

Design of the study. To determine the proportions of the drugs for the mixtures, a pilot study was performed with 10 patients who underwent thyroidectomy with TIVA using remifentanil and propofol infusions separately (the same anesthesia protocol in the control group). The mean infusion rates for remifentanil and propofol were $0.26 \pm 0.09$ and $81 \pm 23 \mu \mathrm{g} / \mathrm{kg} / \mathrm{min}$, respectively. The proportion of total drug consumptions for remifentanil and propofol was 3.2/1,000 in the pilot study, which was supposed to be compared with the routine management at our institution using a drug proportion of $2 / 1,000$.

Statistical analysis. The primary outcome measure was the extubation time after all infusions were stopped. The sample size requirement was based on the preliminary data from the pilot study in which the extubation time was $8 \pm 2.4 \mathrm{~min}$. Thus, at an alpha risk of $0.05,32$ patients per group would provide $80 \%$ statistical power and detect a $50 \%$ difference in extubation time. Secondary outcome measures were the incidence of undesirable events (e.g. hypotension, hypertension, bradycardia, intraoperative movement of the patient).

One-way ANOVA for parametric variables and the Kruskal-Wallis test for non-parametric variables were used. The chi-squared test was used for comparison of adverse effects. The Tukey-Kramer test was used to compare groups individually. All statistical analyses were performed using the commercially available SPSS v.16.0 software package (SPSS Inc.). $\mathrm{P}<0.05$ was considered to indicate statistical significance.

\section{Results}

Enrollment. Of the 146 patients approached, 24 did not meet the criteria for inclusion, 23 refused to participate in the study and the protocol was incorrectly applied in 3, leaving 96 patients suitable to be enrolled in the present trial (Fig. 1).

Demographic characteristics. Data of demographic characteristics of patients are presented in Table II. The age and sex distribution of the patients and other patient characteristics were not significantly different between the groups.

Anesthesia characteristics. While the duration of anesthesia and surgery and the mean propofol infusion rate (total propofol consumption/body weight/infusion time) were comparable between the groups, the mean remifentanil infusion rate (total remifentanil consumption/body weight/infusion time) in Group III was significantly higher when compared with that in the other groups $(\mathrm{P}<0.05)$. The primary outcome of the study (the extubation time) was comparable among the groups (Table III). 


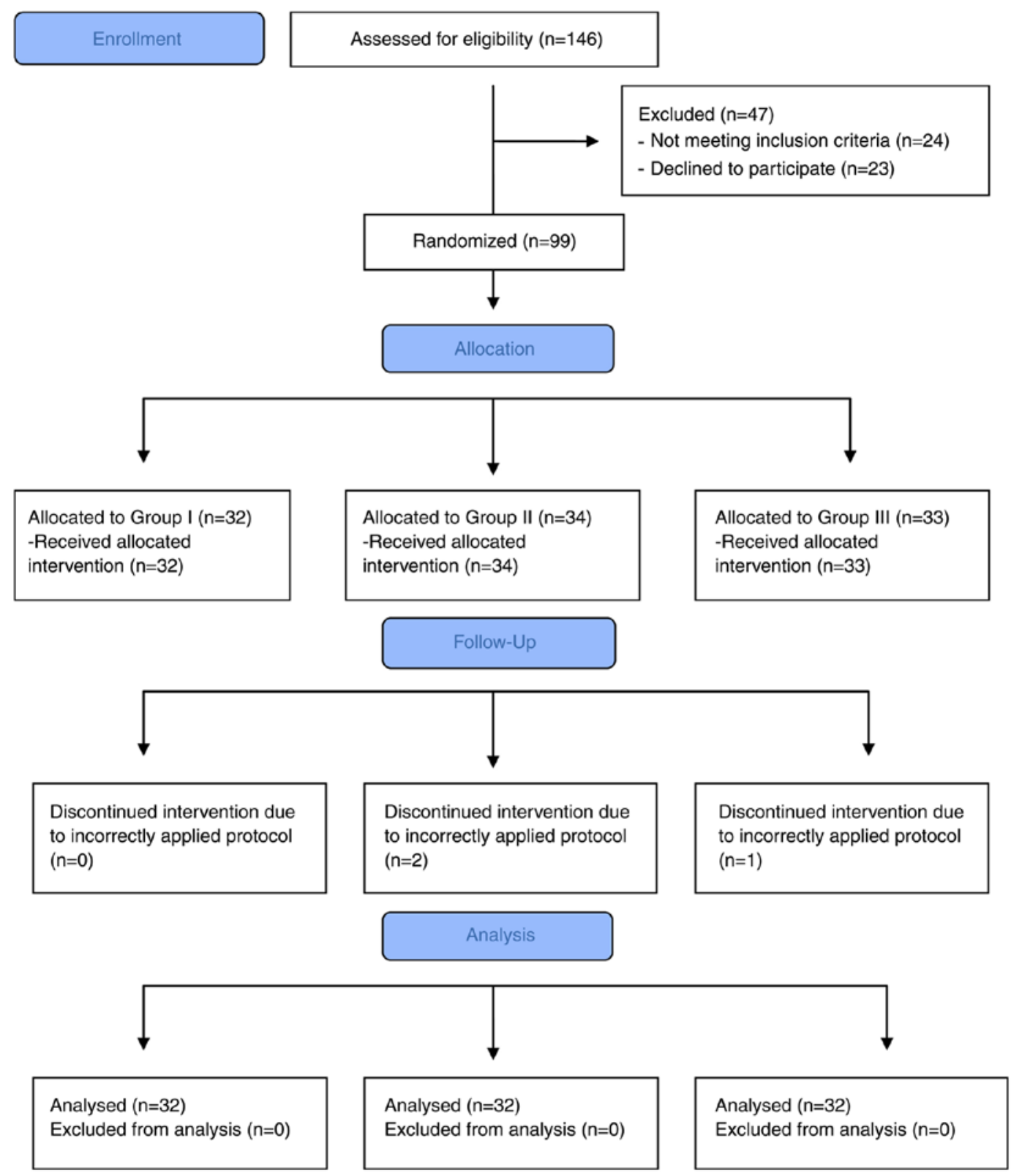

Figure 1. Flow chart of the movement of the participants through each stage of randomization.

Hemodynamics. The numbers of patients in whom intraoperative hypotension, hypertension or bradycardia episodes were encountered during anesthesia were comparable among the groups (Table III). Hypotension episodes were mostly encountered after induction or prior to delayed surgery. Hypertension episodes mostly occurred after endotracheal intubation or at the beginning of delayed surgery.

BIS scores and recovery characteristics. The mean BIS scores (the average of values recorded during anesthesia) and recovery characteristics (extubation and orientation time) of the patients were comparable among groups (Table III). The numbers of patients who had a BIS $>60$ recorded during anesthesia were also comparable (in most of them, BIS was between 60 and 65). A high BIS was mostly encountered after endotracheal intubation or at the beginning of delayed surgery. Hypotension accompanied with a high BIS (up to 70) was encountered in one patient in Group III who was treated with norepinephrine and ketamine (Table III). No intraoperative awareness was noted in any of the groups.

Other adverse events. In addition, no serious respiratory adverse event leading to desaturation (peripheral oxygen saturation $<90 \%$ lasting $>1 \mathrm{~min}$ ) was noted in any of the groups. The incidence of postoperative nausea and vomiting, which required ondansetron administration, and shivering, which required meperidine administration, were also comparable between groups (Table III).

\section{Discussion}

In the present study, TIVA with MIXTIVA (remifentanil/propofol proportion of $2 / 1,000$ or $3 / 1,000$ ) using a single-infusion technique was not associated with any statistically significant difference in clinical outcomes (recovery characteristics, incidence of hemodynamic fluctuations and 
Table III. Anesthesia characteristics.

\begin{tabular}{|c|c|c|c|c|}
\hline Item & Group I $(\mathrm{n}=32)$ & Group II $(n=32)$ & Group III (n=32) & P-value \\
\hline Duration of anesthesia (min) & $103(100-131)$ & $114(101-122)$ & $107(96-114)$ & NS \\
\hline Duration of surgery (min) & $90(88-119)$ & $103(88-108)$ & $92(82-100)$ & NS \\
\hline Mean propofol infusion rate $(\mu \mathrm{g} / \mathrm{kg} / \mathrm{min})$ & $88 \pm 25(79-98)$ & $106 \pm 25(97-115)$ & $100 \pm 41(85-115)$ & NS \\
\hline Mean remifentanil infusion rate $(\mu \mathrm{g} / \mathrm{kg} / \mathrm{min})$ & $0.25 \pm 0.09(0.22-0.29)$ & $0.21 \pm 0.05(0.19-0.23)$ & $0.31 \pm 0.11^{\mathrm{a}}(0.27-0.35)$ & $<0.0001$ \\
\hline Mean BIS value & $41 \pm 5(39-42)$ & $39 \pm 6(37-42)$ & $42 \pm 5(40-44)$ & NS \\
\hline Extubation time (min) & $8(7.2-10.2)$ & $8.5(7.7-10.2)$ & $9.5(8.4-10.8)$ & NS \\
\hline Orientation time (min) & $9(8.6-11.8)$ & $10(9-11.8)$ & $11(9.9-12.8)$ & NS \\
\hline Intraoperative bradycardia & $1(3)$ & $1(3)$ & $0(0)$ & NS \\
\hline Intraoperative hypertension & $5(16)$ & $6(19)$ & $2(6)$ & NS \\
\hline Intraoperative hypotension & $7(22)$ & $6(19)$ & $5(16)$ & NS \\
\hline Sympathomimetic use & $3(9)$ & $1 \quad(3)$ & $2(6)$ & NS \\
\hline Intraoperative movement & $3(9)$ & $2(6)$ & $0(0)$ & NS \\
\hline Additional vecuronium & $4(13)$ & $3(9)$ & $2(6)$ & NS \\
\hline Recorded BIS >60 & $7(22)$ & $6(19)$ & $9(28)$ & NS \\
\hline Ketamine use & $0 \quad(0)$ & $0 \quad(0)$ & $1(3)$ & NS \\
\hline PONV & $3(9)$ & $2(6)$ & $3(9)$ & NS \\
\hline Postoperative shivering & $2(6)$ & $2(6)$ & $3(9)$ & NS \\
\hline
\end{tabular}

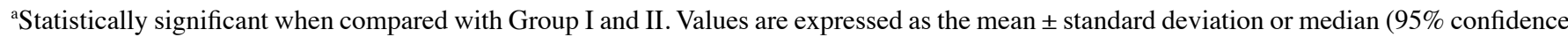
interval) and absolute number of patients (percentage). NS, not significant $(\mathrm{P}>0.05)$; BIS, bispectral index score; PONV, postoperative nausea and vomiting.

other undesirable events) when compared with the standard TIVA technique using separate drug infusions.

Recently, Bagshaw et al (3) evaluated 873 pediatric patients who underwent mostly gastroenterology and ear, nose and throat procedures using MIXTIVA infusion. The incidence of serious adverse events such as desaturation, apnea, abdominal/chest rigidity, cough requiring paralysis, ventilatory problems and hypotension was $1.7 \%$ and they had occurred mostly at induction and were not attributed directly to the use of the mixture itself.

Although it is mostly not recommended, mixing intravenous agents appears to be popular in clinical practice. Propofol is frequently mixed with lidocaine to minimize the injection pain. Mixtures of alfentanil and propofol were used for TIVA before remifentanil became more popular $(28,29)$. Mixtures of ketamine and propofol, 'ketofol', was recommended, particularly for sedation and analgesia for short and painful procedures (30-32). Mixtures of propofol with other intravenous drugs such as thiopental (33), ephedrine (34), methohexital (35) and metoclopramide (36), and mixtures of remifentanil with tramadol (37) have been reported, but most of these implementations may be considered as 'experimental'.

In the literature, remifentanil-propofol mixture has been used mostly for patient-controlled sedation $(9,10,12,17)$ or deep sedation with spontaneous ventilation $(5-8,11,13,14,16,18,19)$. Research on the use of MIXTIVA for maintenance of general anesthesia is limited $(1,3,15,20,22)$. While certain recommendations have been given for MIXTIVA usage in general anesthesia (23-25), the remifentanil/propofol proportion varies $(0.5 / 1,000$ to $5 / 1,000)$ among centers and the possible drawbacks of this technique and optimum proportion of drugs remain to be investigated.

Stewart et al (26) demonstrated that remifentanil and propofol may be mixed in polypropylene syringes and used for up to $36 \mathrm{~h}$ when the remifentanil/propofol proportion was $5 / 1,000$. However, when polyvinylchloride bags and lower concentrations of remifentanil were used $(0.5 / 1,000)$, the duration of stability was decreased to $1 \mathrm{~h}$. O'Connor et al (27) reported that when remifentanil solution and propofol emulsion were mixed in the same syringe, separation and layering of the drugs may result in significant differences of drug concentrations at the top and bottom of the syringe (remifentanil having a greater concentration at the top and propofol having a greater concentration at the bottom of the syringe). The lack of control groups (drugs also had to be evaluated separately without mixing) may be the major limitation of that study. In addition, they measured drug concentrations at the top and bottom of vertically mounted syringes, while in most of the syringe infusion pumps in clinical use, syringes are mounted horizontally and the drug mixture exits the syringe from the midpoint of the mixture instead of the bottom. In the present study, volumetric pumps were used and the mixtures were prepared immediately prior to infusion in 50-ml glass bottles of propofol instead of polypropylene syringes and mixtures were used within $<2 \mathrm{~h}$.

The use of MIXTIVA infusion may be recommended to clinicians after gaining experience with the standard TIVA technique using separate drug infusions and administrating propofol infusion with the guidance of BIS monitoring. In clinical practice, BIS monitoring is not common and in order to decrease the risk of awareness and recall during 
TIVA, premedication with midazolam, adding ketamine $0.3-0.5 \mathrm{mg} / \mathrm{kg}$ to the anesthesia protocol and (as the movement of the patient under general anesthesia constitutes a warning of rising consciousness or pain) minimizing the use of neuromuscular blocking agents (NMBAs) during TIVA are recommended. General anesthesia for short procedures using a laryngeal mask airway without NMBAs appears to be best suited for MIXTIVA technique. Adjusting the remifentanil/propofol proportion of MIXTIVA according to the type of surgery (increasing the proportion for more painful procedures or hypotensive anesthesia) or to the condition of the patient (decreasing the proportion in elderly patients) may be favorable. According to the pharmacokinetics of propofol, for a constant blood or effect-site concentration, a gradual decrease in the initial propofol infusion rate is required (2). For long procedures ( $>2 \mathrm{~h}$ ), it may be preferred to gradually increase the proportion, starting with $2 / 1,000$ in the first $50 \mathrm{ml}$ (with or without ketamine administration) and continuing with 3-4/1,000 in the following.

The primary outcome of the recent study was the extubation time and sample size estimation was performed according to this outcome. As a consequence, the study may be underpowered to obtain any differences in other clinical outcomes. In addition, a 'BIS-blinded' study would be more appropriate to determine the risk of awareness.

In conclusion, compared with the standard TIVA technique using separate drug infusions, when TIVA, using a single-infusion technique with MIXTIVA (remifentanil/propofol proportion, 2/1,000 or 3/1,000) was applied for thyroidectomies, no statistically significant difference in recovery and clinical outcome was obtained. This technique may be considered as a practical implementation for busy ambulatory surgery centers performing general anesthesia. Adjustment of the remifentanil-propofol proportion for different types of surgery and patient groups must be considered and further studies with larger patient populations are warranted.

\section{Acknowledgements}

The results of the present study were presented on a poster at the 47th National Congress of the Turkish Society of Anesthesiology and Reanimation (20-24 October 2013; Abstract no. P-27: Antalya, Turkey).

\section{Funding}

No funding was received.

\section{Availability of data and materials}

The datasets used and/or analyzed during the current study are available from the corresponding author on reasonable request.

\section{Authors' contributions}

MB designed the study. MB and TU were involved in performing the study procedures, data analysis and writing of the manuscript. UT contributed to data analysis and writing of the manuscript. EYG and HU were involved in performing the study procedures and data analysis. EO contributed to design of the study and was involved in writing the manuscript. All authors confirm the authenticity of the raw data, and read and approved the final manuscript.

\section{Ethics approval and consent to participate}

The present study was approved by the Ethics Committee of Bezmialem Vakif University (Istanbul, Turkey; reference no. 71306642/050-01-04). Informed consent was obtained from all individual participants included in the study.

\section{Patient consent for publication}

Not applicable.

\section{Competing interests}

The authors declare that they have no competing interests.

\section{References}

1. Anderson BJ and Bagshaw O: Practicalities of total intravenous anesthesia and target-controlled infusion in children. Anesthesiology 131: 164-185, 2019.

2. Roberts FL, Dixon J, Lewis GT, Tackley RM and Prys-Roberts C: Induction and maintenance of propofol anaesthesia. A manual infusion scheme. Anaesthesia 43 (Suppl): S14-S17, 1988.

3. Bagshaw O, McCormack J, Brooks P, Marriott D and Baxter A: The safety profile and effectiveness of propofol-remifentanil mixtures for total intravenous anesthesia in children. Paediatr Anaesth 30: 1331-1339, 2020.

4. Bagshaw O: Pediatric anesthesia editorial-propofol and remifentanil: To mix or not to mix. Paediatr Anaesth 26: 677-679, 2016.

5. Goudra BG, Singh PM and Sinha A: Providing anesthesia in a remote location for radiation oncology in an adult-Problems and solutions. J Anaesthesiol Clin Pharmacol 30: 114-116, 2014.

6. Pedersen NA, Jensen AG, Kilmose L and Olsen KS: Propofol-remifentanil or sevoflurane for children undergoing magnetic resonance imaging? A randomized study. Acta Anaesthesiol Scand 57: 988-995, 2013.

7. Lan C, Shen X, Cui H, Liu H, Li P, Wan X, Lan L and Chen D: Comparison of nitrous oxide to no sedation and deep sedation for diagnostic upper gastrointestinal endoscopy. J Gastrointest Surg 17: 1066-1072, 2013

8. Kramer KJ, Ganzberg S, Prior S and Rashid RG: Comparison of propofol-remifentanil versus propofol-ketamine deep sedation for third molar surgery. Anesth Prog 59: 107-117, 2012.

9. Joo JD, In JH, Kim DW, Jung HS, Kang JH, Yeom JH, Yeom JH and Choi JW: The comparison of sedation quality, side effect and recovery profiles on different dosage of remifentanil patient-controlled sedation during breast biopsy surgery. Korean J Anesthesiol 63: 431-435, 2012.

10. Mazanikov M, Udd M, Kylänpää L, Mustonen H, Lindström O, Halttunen J, Färkkilä M and Pöyhiä R: Patient-controlled sedation for ERCP: A randomized double-blind comparison of alfentanil and remifentanil. Endoscopy 44: 487-492, 2012.

11. Ryu JH, Kim M, Bahk JH, Do SH, Cheong IY and Kim YC: A comparison of retrobulbar block, sub-Tenon block, and topical anesthesia during cataract surgery. Eur J Ophthalmol 19: 240-246, 2009.

12. Mandel JE, Tanner JW, Lichtenstein GR, Metz DC, Katzka DA, Ginsberg GG and Kochman ML: A randomized, controlled, double-blind trial of patient-controlled sedation with propofol/remifentanil versus midazolam/fentanyl for colonoscopy. Anesth Analg 106: 434-439, 2008.

13. Melville D, Hartsilver EL and Hart A: Bolus dosing of remifentanil with propofol for gynaecological day case surgery. J One Day Surg 18: 88-91, 2008.

14. Tsui BC, Wagner A, Usher AG, Cave DA and Tang C: Combined propofol and remifentanil intravenous anesthesia for pediatric patients undergoing magnetic resonance imaging. Paediatr Anaesth 15: 397-401, 2005 
15. Brady WJ, Meenan DR, Shankar TR, Balon JA and Mennett DR: Use of a remifentanil and propofol combination in outpatients to facilitate rapid discharge home. AANA J 73: 207-210, 2005.

16. Berkenbosch JW, Graff GR, Stark JM, Ner Z and Tobias JD: Use of a remifentanil-propofol mixture for pediatric flexible fiberoptic bronchoscopy sedation. Paediatr Anaesth 14: 941-946, 2004.

17. Joo HS, Perks WJ, Kataoka MT, Errett L, Pace K and Honey RJ: A comparison of patient-controlled sedation using either remifentanil or remifentanil-propofol for shock wave lithotripsy. Anesth Analg 93: 1227-1232, 2001.

18. Fish WH, Hobbs AJ and Daniels MV: Comparison of sevoflurane and total intravenous anaesthesia for daycase urological surgery. Anaesthesia 54: 999-1006, 1999.

19. Anderson BJ and Houghton J: Total intravenous anesthesia and target-controlled infusion. In: A Practice of Anesthesia for infants and children. 6th edition. Cote CJ, Lerman $\mathbf{J}$ and Anderson BJ (eds). Elsevier, pp177-198, 2019.

20. Bennett JD and Butterfield K: Anesthetic concepts and techniques. Vol. 1. In: Oral and Maxillofacial Surgery. 3rd edition. Fonseca RJ (ed). Elsevier, St. Louis, MO, pp211-224, 2018.

21. Robert RC, Liu S, Patel C and Gonzalez ML: Advancements in office-based anesthesia in oral and maxillofacial surgery. Atlas Oral Maxillofac Surg Clin North Am 21: 139-165, 2013.

22. Urman RD and Shapiro FE: Choosing anesthetic agents. Which one? In: Manual of Office-Based Anesthesia Procedures. Shapiro FE (ed). Lippincott Williams \& Wilkins, Philadelphia, PA, pp58-74, 2007.

23. https://www.rch.org.au/uploadedFiles/Main/Content/anaes/TIVA\% 20for\%20tonsillectomy\%202014.pdf, Assessed October, 2020.

24. http://www.anesthesiologynews.com/ViewArticle.aspx?d_id=1\&a_ id=14586\&ses=ogst. Assessed October, 2020.

25. http://ether.stanford.edu/library/pediatric_anesthesia/anesthetic\% 20techniques/guideline-tiva.pdf. Assessed October, 2020

26. Stewart JT, Warren FW, Maddox FC, Viswanathan K and Fox JL: The stability of remifentanil hydrochloride and propofol mixtures in polypropylene syringes and polyvinylchloride bags at 22 degrees-24 degrees C. Anesth Analg 90: 1450-1451, 2000.
27. O'Connor S, Zhang YL, Christians U, Morrison JE Jr and Friesen RH: Remifentanil and propofol undergo separation and layering when mixed in the same syringe for total intravenous anesthesia. Paediatr Anaesth 26: 703-709, 2016.

28. Wilson RJ and Ridley SA: The use of propofol and alfentanil by infusion in military anaesthesia. Anaesthesia 47: 231-233, 1992.

29. Collins SJ, Robinson AL and Holland HF: A comparison between total intravenous anaesthesia using a propofol/alfentanil mixture and an inhalational technique for laparoscopic gynaecological sterilization. Eur J Anaesthesiol 13: 33-37, 1996.

30. Weatherall A and Venclovas R: Experience with a propofol-ketamine mixture for sedation during pediatric orthopedic surgery. Paediatr Anaesth 20: 1009-1016, 2010.

31. Lamperti M: Adult procedural sedation: An update. Curr Opin Anaesthesiol 28: 662-667, 2015.

32. Ghojazadeh M, Sanaie S, Paknezhad SP, Faghih SS and Soleimanpour H: Using ketamine and propofol for procedural sedation of adults in the emergency department: A systematic review and meta-analysis. Adv Pharm Bull 9: 5-11, 2019.

33. Fahringer DL, Goodwin SR, Warde MK, Ye G, Blackwelder B, Ajala AM and Gurgis FS: The effect of a 3: 1 volume mixture of propofol $1 \%$ and thiopental $2.5 \%$ in reducing the pain on injection of propofol in children. Paediatr Anaesth 20: 545-552, 2010.

34. Austin JD and Parke TJ: Admixture of ephedrine to offset side effects of propofol: A randomized, controlled trial. J Clin Anesth 21: 44-49, 2009.

35. Thompson $\mathrm{N}$ and Robertson GS: Comparison of propofol and a propofol-methohexitone mixture for induction of day-case anaesthesia. Br J Anaesth 77: 213-216, 1996.

36. Mecklem DW: Propofol injection pain: Comparing the addition of lignocaine or metoclopramide. Anaesth Intens Care 22: 568-570, 1994

37. Unlugenc H, Tetiker S and Isik G: Addition of remifentanil to patient-controlled tramadol for postoperative analgesia: A double-blind, controlled, randomized trial after major abdominal surgery. Eur J Anaesthesiol 25: 968-975, 2008. 